\title{
Qualidade funcional da infusão do chá verde comercial
}

\author{
Functional quality of commercial \\ green tea
}

Jane Delane Reis PIMENTEL-SOUZA ${ }^{1}$

Danilo Santos SOUZA ${ }^{1}$

Nayjara Carvalho GUALBERTO'

Suyare Araújo RAMALHO ${ }^{1}$

Jane de Jesus da Silveira MOREIRA ${ }^{1}$

Narendra NARAIN ${ }^{1}$

\section{R E S U M O}

\section{Objetivo}

O objetivo deste trabalho foi avaliar a qualidade de duas marcas comerciais de chá verde em sachê, e verificar o efeito do tempo de infusão, em intervalos de tempos que incluem o recomendado pelo fabricante, sobre a disponibilidade dos compostos funcionais.

\section{Métodos}

Por análises em cromatografia líquida ultrarrápida com detector de arranjos de díodo,foram identificadas e quantificadas a cafeína, a catequina, a epigalocatequina, a rutina e a epicatequina.

\section{Resultados}

A epigalotocatequina e a catequina foram encontradas em maior concentração no tempo seis minutos de infusão em água $\left(100^{\circ} \mathrm{C}\right)$ em ambas as marcas, sendo a rutina apenas encontrada na infusão por seis minutos e em apenas uma das marcas avaliadas. A extraçãocom metanol $(99,8 \%)$ aumentou significativamente o rendimento de todos os compostos avaliados. Foi observado que atividade antioxidante equivalente ao trolox do chá aumentou diretamente com o aumento do tempo de infusão, no entanto, para os extratos obtidos em metanol, a atividade antioxidante foi menor que todos os outros tratamentos, havendo diferença significativa $(p<0,05)$.

\section{Conclusão}

As análises químicas de umidade, cinzas e cinzas insolúveis em ácido clorídrico revelaram que as duas marcas avaliadas estão em conformidade com a legislação para esses parâmetros, bem como com relação à presença de sujidades e materiais estranhos, revelados na microscopia.

Termos de indexação: Antioxidantes. Camellia sinensis. Flavonoides. Gestão de qualidade.

\footnotetext{
1 Universidade Federal de Sergipe, Centro de Ciências Exatas e Tecnologia, Departamento de Tecnologia de Alimentos. Av. Marechal Rondon, s/n., 49100-000, São Cristóvão, SE, Brasil. Correspondência para/Correspondence to: JDR PIMENTEL-SOUZA. E-mail: <jane.delane@hotmail.com>.
} 


\section{A B S T R A C T}

\section{Objective}

The objective of this study was to assess the quality of two commercial brands of green tea in sachets, verifying how different infusion times, including that recommended by the manufacturer, affect functional component levels.

\section{Methods}

High-performance liquid chromatography with diode-array detection was used for identifying and quantifying caffeine, catechin, epigallocatechin, rutin and epicatechin.

\section{Results}

Epigallocatechin and catechin levels of both brands were higher with an infusion time of 6 minutes in boiling water $\left(100^{\circ} \mathrm{C}\right)$. Rutin was only found in one of the brands after an infusion of six minutes. Methanol (99.8\%) extraction significantly increased the yield of all study compounds. The Trolox Equivalent Antioxidant Capacity of the tea increased with infusion time. However, the Trolox Equivalent Antioxidant Capacity of the methanol extractions was significantly smaller than that of all of the other treatments $(p<0.05)$.

\section{Conclusion}

Chemical analysis of moisture, ash, ash insoluble in hydrochloric acid, and microscopic analysis of dirt and other physical contaminants showed that both brands conform to the legislation with respect to these parameters.

Indexing terms: Antioxidantes. Camellia sinensis. Flavonoids. Quality management

\section{N T R O D U Ç Ã O}

A apreciação do chá verde (Camelia sinensis L. Kuntze) deve-se ao seu aroma, ao seu sabor e às suas propriedades funcionais, mundialmente conhecidas. A praticidade do consumo do chá verde em sachê torna o hábito de consumi-lo muito comum entre os que apreciam a bebida.

Conforme consta na legislação ${ }^{1}$, o chá de Camelia sinensis (L.) Kuntze deve ser constituído por folhas e brotos, inteiros ou fragmentados, sendo o chá verde um produto não fermentado, submetido à secagem.

Para ser obtido o chá verde, as folhas são picadas e brevemente aquecidas para inativar a polifenol-oxidase, impedindo assim que o processo de oxidação ocorra antes de as folhas serem secas $^{2}$. No mundo, são produzidos anualmente cerca de três bilhões de toneladas de chá, sendo $20 \%$ de chá verde ${ }^{3,4}$.

Muitos estudos têm demonstrado os benefícios para a saúde do consumo de chá verde, que auxilia na prevenção do câncer ${ }^{5}$, dos tumores de fígado $^{6}$, das doenças cardiovasculares ${ }^{7}$ e da hipertensão ${ }^{8}$. Os flavonoides são amplamente reconhecidos por suas propriedades antioxidantes $^{9,5}$. De forma geral, a atividade antioxidante está relacionada à prevenção de várias doenças, incluindo arteriosclerose, doenças do fígado, obesidade $^{10}$ e vários tipos de câncer ${ }^{4,11,12}$.

$\mathrm{Na} C$. Sinensis, os flavonoides constituem cerca de $10 \%$ a $25 \%$ da matéria seca de folhas jovens e brotos, sendo denominados de catequinas ${ }^{13,4}$ e classificados nos subgrupos: Catequina Simples (C), Epicatequina (EC), Galatoepicatequina (ECG), Epigalocatequina (EGC), Galatoepigalocatequina (EGCG) e Galocatequina-galato (GCG). Além das catequinas, no chá verde estão presentes outros importantes compostos orgânicos, entre eles a cafeína e muitos aminoácidos ${ }^{14,15}$. O chá verde propriamente dito é feito de folhas mais novas e tenras. A diferença da matéria-prima reflete-se no sabor, na cor e, possivelmente, nos teores de catequinas ${ }^{16}$.

Nos últimos anos, a produção mundial de chá tem aumentado mais do que o consumo ${ }^{17} \mathrm{e}$ a concorrência de mercado tornou sua qualidade o parâmetro mais importante para o estabelecimento do preço ${ }^{18}$. Visando a garantir padrões mínimos de qualidade para a comercialização de chá, 
a Agência Nacional de Vigilância Sanitária (ANVISA) estabeleceu parâmetros de qualidade para os chás comerciais, como classificação, características de composição, sensoriais, físico-químicas, microscópicas, entre outros ${ }^{1}$.

No Brasil, o chá verde é comercializado principalmente em sachês individuais armazenados em pequenas caixas, o que facilita seu consumo e ajuda a difundi-lo. Embora sejam muitos os estudos sobre a presença dos compostos bioativos do chá, principalmente quanto aos teores de catequina presentes ${ }^{11,16,19}$, relatos sobre a qualidade de comercialização desse produto e sobre a conformidade das marcas comerciais com os parâmetros de qualidade estabelecidos pela legislação ainda são escassos. Estudos que demonstram a disponibilidade dos compostos funcionais na infusão do chá no momento do consumo, de acordo com as condições usuais de preparo pelo consumidor, também se fazem necessários. Dessa forma, é de grande importância estudar o perfil da qualidade do chá verde disposto para comercialização no Brasil e a eficiência no tempo de preparo.

Um dos métodos mais utilizados para medir a atividade antioxidante de chás é a captura do radical (2,2'-azinobis(3-etilbenzotiazolina-6ácido sulfônico)) (ABTS) ${ }^{15}$, pela qual se pode medir a atividade de compostos de natureza hidrofílica e lipofílica ${ }^{20}$.

Pesquisas recentes apontam a influência da temperatura de infusão sobre a disponibilidade de compostos funcionais no chá verde, em detrimento de trabalhos que relatam o efeito do tempo de infusão sobre essas mesmas características ${ }^{21,22}$.

Nesse contexto, o presente trabalho teve como objetivo avaliar a qualidade de duas marcas comerciais de chá verde em sachê, verificando sua conformidade com os parâmetros estabelecidos na legislação e aferindo o efeito do tempo de infusão do chá verde sobre a disponibilidade dos compostos funcionais ${ }^{1}$.

O presente trabalho foi desenvolvido em 2010, no curso de Pós-Graduação em Ciência e
Tecnologia dos Alimentos, na Universidade Federal de Sergipe. Foram realizadas as análises físico-químicas de umidade, cinzas totais e cinzas insolúveis em ácido clorídrico, e análises físicas por microscopia para verificar a conformidade dos chás quanto ao parâmetro sujidades. A disponibilidade dos compostos funcionais foi avaliada em extratos aquosos (infusões) e extrato metanólico por meio da determinação da Atividade Antioxidante Equivalente ao Trolox (Trolox Equivalent Antioxidant Capacity - TEAC), e por identificação e quantificação dos compostos funcionais (cafeína, catequina, rutina, epicatequina e epigalatocatequina) por Cromatografia Líquida Ultrarrápida com Detector de Arranjos de Díodo (CLUR-DAD).

\section{M É T O D O S}

\section{Amostras}

As duas marcas de chá verde utilizadas neste estudo foram adquiridas no comércio local (Aracajú, Sergipe) e foram produzidas no Brasil: uma no estado do Paraná (marca 1) e outra no estado de São Paulo (marca 2). As embalagens continham dez sachês com 1,6g (marca 1) e 1,7g (marca 2) em média cada um.

\section{Reagentes}

Trolox (Ácido 6-Hidroxi-2,5,7,8-tetrametilcromano-2-carboxílico), ABTS (2,2'-AzinoBis-(Ácido 3-etilbenzotianzolina-6-sulfônico), sal diamônico e padrões de (+)-hidrato de catequina $\geq 96 \%$, (-)-epicatequina extrato de chá verde $\geq 98 \%$, hidrato de rutina $>95 \%$ e cafeína $99 \%$ utilizados neste estudo foram adquiridos da Sigma-Aldrich Corporation (São Paulo, Brasil), e o persulfato de potássio P. A., da Synth (São Paulo, Brasil).

\section{Preparo do chá}

Nas duas marcas de chá verde, foram estudados o conteúdo seco do sachê, extraído com 
metanol P.A., e os tempos de infusão em água $(1,5 ; 3$ e 6 minutos). As infusões foram preparadas imergindo um sachê de chá em $150 \mathrm{~mL}$ de água a $100^{\circ} \mathrm{C}$. Utilizou-se como referência a recomendação para preparo do chá contida na embalagem: imersão do sachê em uma xícara de chá com água fervente, por três minutos. Como o tempo de imersão pode ser um fator para biodisponibilidade de compostos, utilizou-se um tempo acima e um tempo abaixo do recomendado na embalagem. Para a análise do extrato do chá desidratado, o sachê foi imerso em $30 \mathrm{~mL}$ de metanol grau cromatográfico à temperatura ambiente (Média$-\mathrm{M}=22^{\circ} \mathrm{C}$, Desvio-Padrão-DP=2) por 10 minutos. Todos os extratos foram filtrados a vácuo, em papel filtro ${ }^{23}$, e os experimentos e análises foram realizados em triplicata genuína.

\section{Avaliação do perfil dos compostos funcionais por CLUR - DAD}

Para cada extrato de chá, foi retirada uma alíquota para filtração em membrana de nylon $(0,45 \mu \mathrm{m})$, marca Maxcrom OEM. Desse filtrado, $2 \mu \mathrm{L}$ foram injetados na coluna cromatográfica. Os flavonoides foram separados e quantificados em coluna Shimadzu XR-ODS (50Lx3.0x2,2 $\mu \mathrm{m})$, de acordo com metodologia adaptada de Nishiyama et al. ${ }^{19}$ e Saito et al. ${ }^{24}$. O equipamento utilizado foi um cromatógrafo a líquido ultrarrápido LC-20AD (Shimadzu), equipado com desgaseificador, bomba binária (LC-20AD), injetor automático (SIL-20A) e detector de arranjo de díodos UVNIS - DAD (SPD-M20A) com monitoramento na faixa de 190 a 800nm.

A eluição foi realizada de forma isocrática e teve como fase móvel o solvente A, água: acetonitrila: metanol: acetato de etila: ácido acético glacial (89:6:1:3:1) com um fluxo de $0,4 \mathrm{~mL} / \mathrm{mi}-$ nuto por 10 minutos. Todas as análises foram realizadas a $M=40, D P=2^{\circ} \mathrm{C}$. Para identificar os principais bioativos do chá verde, padrões de cafeína, catequina, rutina e epicatequina foram aplicados isoladamente, seguindo a mesma metodologia.
A quantificação da (+) catequina hidratada (Sigma-Aldrich, 98\%) e da cafeína (Sigma-Aldrich, 98\%) foram realizadas pelo método do padrão externo, e as curvas de calibração com diluição de 10 pontos.

\section{Determinação da atividade antioxidante total}

A atividade antioxidante determinada pelo método ABTS foi realizada conforme metodologia descrita por Rufino et al. ${ }^{20}$. O radical ABTS •+, formado pela reação de $7 \mathrm{mM}$ de ABTS com $140 \mathrm{mM}$ de persulfato de potássio, foi armazenado no escuro, à temperatura ambiente, por 16 horas. Uma vez formado, o radical foi diluído com etanol até a obtenção da absorbância a 754nm de $M=0,700, D P=0,05)$. A partir de cada extrato de chá foram preparadas três diluições diferentes. Em ambiente escuro, uma alíquota de $30 \mu \mathrm{L}$ de cada diluição do extrato foi transferida para tubos de ensaio, e $3 \mathrm{~mL}$ do radical $A B T S \bullet+$ foram adicionados. As absorbâncias foram então lidas a $734 n m$, após seis minutos da reação, utilizando o etanol como branco. O Trolox foi utilizado como antioxidante padrão para a curva de calibração nas concentrações de $100 \mu \mathrm{M}$ a $2.000 \mu \mathrm{M}$, e o resultado foi expresso em equivalente de $\mu \mathrm{M}$ Trolox/g de matéria seca ${ }^{20}$.

\section{Análises químicas}

As determinações de umidade, cinzas totais e cinzas insolúveis em ácido clorídrico foram realizadas em triplicata, seguindo a metodologia do Instituto Adolfo Lutz ${ }^{25}$. Essas análises foram feitas com amostras secas (conteúdo dos sachês) apenas, sendo utilizadas para avaliar a qualidade dos chás, conforme estabelecido na legislação'.

\section{Análises microscópicas}

Em uma quantidade de $10 \mathrm{~g}$ de cada amostra de chá verde, fez-se a microscópia por meio do microscópio digital USB, modelo DM130U 
(Miview), e software Miviewcap. Foi retirado o conteúdo dos sachês até se obterem $10 \mathrm{~g}$ para análise. Esse material foi levado para uma bancada forrada com fundo branco para avaliação cuidadosa de toda a amostra, sendo separados os materiais estranhos encontrados, para posterior contagem e/ou pesagem.

\section{Análise estatística}

A análise estatística dos dados foi realizada pelo programa Statistica 7.0 for Windows, e os dados submetidos à análise de variância de comparação de médias da Análise de Variância (Anova) e ao teste de Tukey $(p<0,05)$.

\section{RESULTADOS E DISCUSSÃO}

\section{Concentrações de catequina, epigalatocatequina, rutina e epicatequina em função do tempo de infusão em água do chá verde}

A análise da fração metanólica e das três infusões aquosas de chá verde foi realizada em sistema CLUR-DAD, em que foram caracterizados os flavonoides catequina, epicatequina, epigalatocatequina e rutina pela comparação entre os tempos de retenção dos compostos com padrões de referência e a confirmação, a partir da similaridade entre os espectros de absorbância, dos compostos e dos padrões, na região ultravioleta. A eluição dos flavonoides da coluna cromatográfica foi monitorada a $280 \mathrm{~nm}$ para os flavonoides catequina, epicatequina, epigalatocatequina e $370 \mathrm{~nm}$ para a rutina. Procedimento semelhante foi adotado para a presença da cafeína nos extratos, monitorada a $230 \mathrm{~nm}$.

As Figuras 1 e 2 apresentam os perfis cromatográficos dos extratos metanólicos a 99,8\% em metanol para as duas marcas avaliadas de chá verde e em tempos de infusão aquosa que variaram de 1,5 a 6 minutos.

Os compostos catequina e cafeína foram selecionados para servirem como padrões na obtenção das curvas de calibração externa. A cafeína foi quantificada a partir da equação de regressão linear, onde $y=2.10^{7} X-7614,5$ $\left(R^{2}=0,9994\right)$; para a catequina, a equação obtida foi $y=91928 X-8433\left(R^{2}=0,999\right)$. Os compostos epicatequina, epigalatocatequina e rutina foram quantificados usando-se como referência a catequina. Os resultados são expressos em catequina mg/100g de chá verde.

O perfil extrativo dos compostos funcionais, observado em função do tempo de infusão dos chás em água, foi semelhante para as amostras analisadas. Foi observado um aumento da concentração (mg/100g) extraída de compostos fenólicos para três dos quatro compostos quantificados, em todos os tratamentos aplicados (Tabela 1). O flavonoide rutina não foi detectado em quantidades quantificáveis na maioria das amostras de infusão de chá verde avaliadas. No entanto, catequina e epigalatocatequina apresentaram comportamento extrativo semelhante nas amostras de chá verde analisadas, sendo o tempo de infusão de seis minutos o tempo de preparo ideal para garantir a maior extração desses compostos, embora os fabricantes dos chás avaliados indiquem o tempo de três minutos de infusão.

Houve diferenças significativas pelo teste de Tukey $(p<0,05)$ entre todos os tratamentos aplicados. Dentre as extrações, a epigalatocatequina se apresentou como o composto em maior concentração ( $M 1=0,86, D P=0,02 \mathrm{mg} / 100 \mathrm{~g}$; $M 2=0,70, D P=0,02 \mathrm{mg} / 100 \mathrm{~g}$ ) para a infusão por seis minutos, o que referenda os dados apresentados por Romeo et al. ${ }^{26}$, com índices semelhantes aos observados por Pekal et al. ${ }^{27}$, para as infusões de chá verde em tempo de infusão de cinco minutos. Dentre as infusões, o tratamento de 1,5 minuto em água a $100^{\circ} \mathrm{C}$ foi o que menos extraiu os compostos estudados do chá verde para ambas as marcas, apresentando diferença significativa entre elas $(p<0,05)$ (Tabela 1).

A concentração de catequina diferiu significativamente $(p<0,05)$ para os três tratamentos em infusão (1,5; 3 e 6 minutos), e, comparativamente, entre as infusões e a extração em metanol 

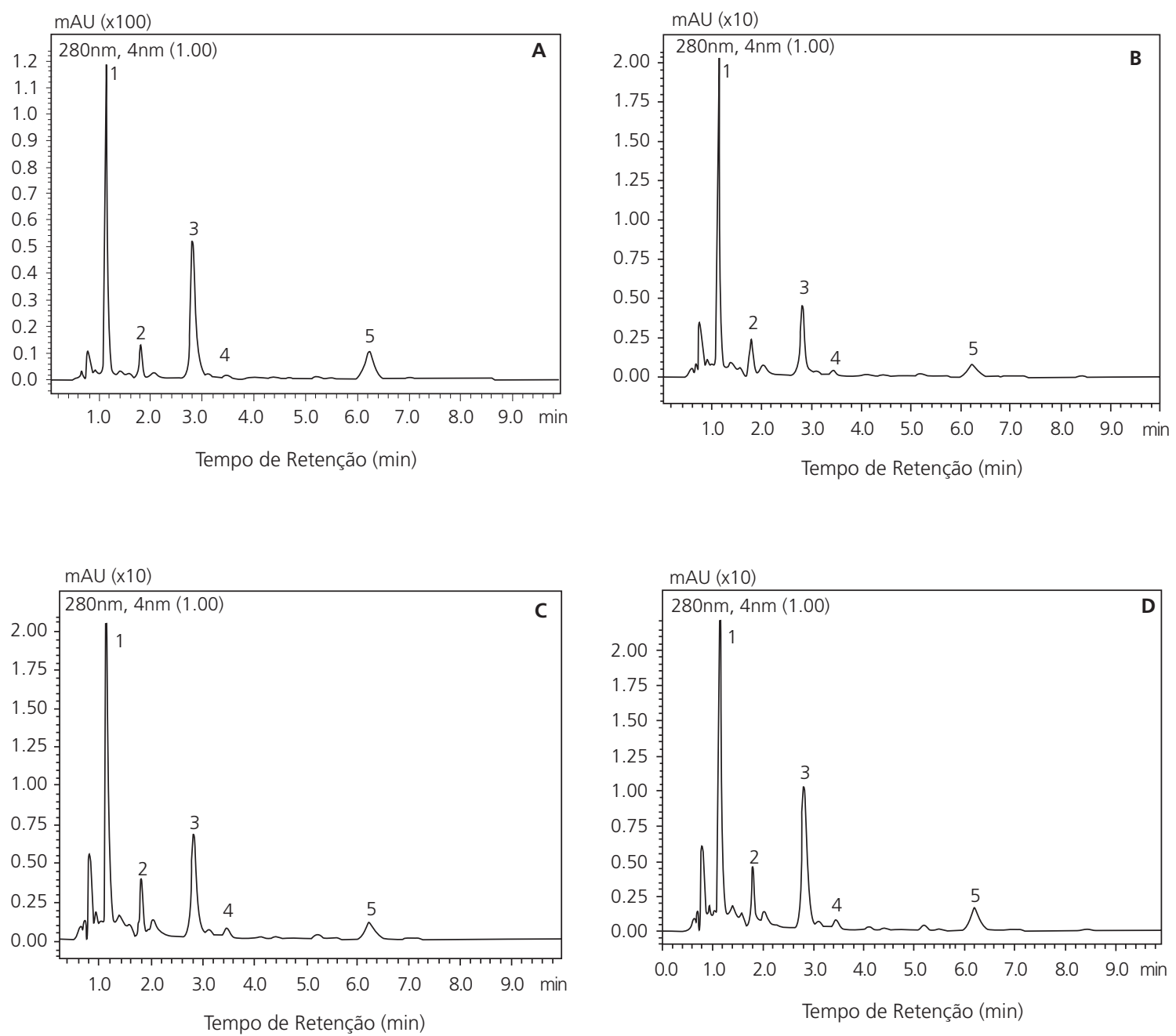

Figura 1. Perfil cromatográfico das amostras de chá verde da Marca 1 identificados por UFLC. (A) Extração por metanol 99,8\%; (B) Infusão em água a $100^{\circ} \mathrm{C}$ por 1,5 minutos; (C) Infusão em água a $100^{\circ} \mathrm{C}$ por 3 minutos; (D) Infusão em água a $100^{\circ} \mathrm{C}$ por 6 minutos.

Nota: 1: cafeína; 2: catequina; 3: epigalocatequina galato; 4: rutina; 5: epicatequina.

$99,8 \%$. No entanto, o tratamento 1,5 minuto em infusão não apresentou diferença significativa para as concentrações de catequina entre as marcas avaliadas. Segundo Nishiyama et al. ${ }^{19}$, o tempo de infusão tem grande influência na quantidade de compostos fenólicos extraídos: um maior tempo de exposição à temperatura extrairá maior quantidade de compostos bioativos, o que corrobora os resultados encontrados neste trabalho.

A diferença nos teores dos flavonoides detectados nas marcas estudadas neste trabalho está de acordo com os relatos de Pelillo et al. ${ }^{28}$, em trabalho que avaliou cinco diferentes marcas comercias de chá verde.

A extração dos compostos fenólicos com etanol a 99,8\% foi superior às extrações aquosas para os mesmos compostos em estudo. A epigalatocatequina foi extraída em maior quantidade nas amostras analisadas, chegando a $M=24,76$, $\mathrm{DP}=1,19 \mathrm{mg} / 100 \mathrm{~g}$, e a rutina esteve presente na extração alcoólica em teores médios de $0,57 \mathrm{mg} /$ $100 \mathrm{~g}$.

Neste estudo, também foi avaliada a influência do tempo de infusão sobre a extração 

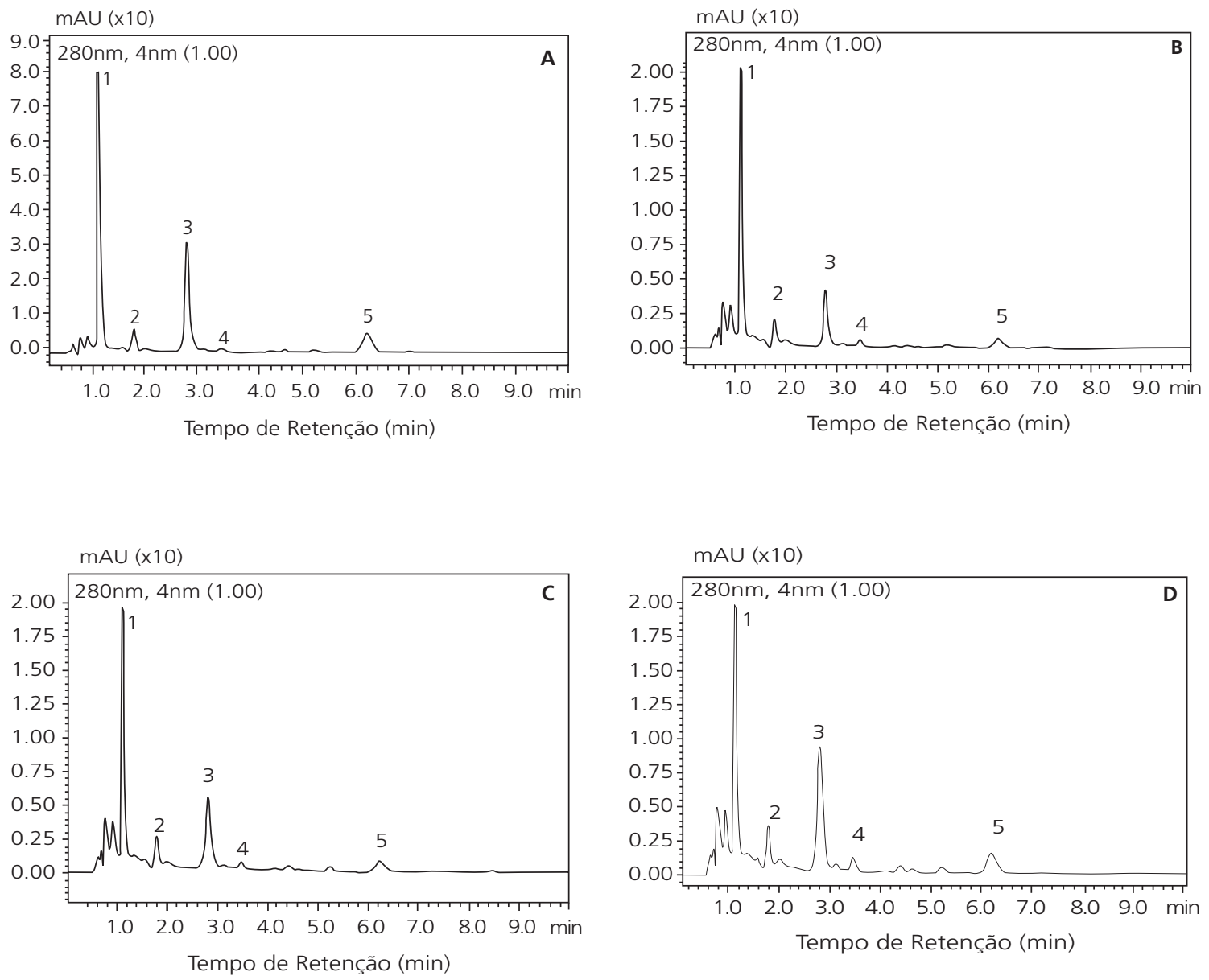

Figura 2. Perfil cromatográfico das amostras de chá verde da Marca 2 identificados por UFLC. (A) Extração por metanol 99,8\%; (B) Infusão em água a $100^{\circ} \mathrm{C}$ por 1,5 minutos; (C) Infusão em água a $100^{\circ} \mathrm{C}$ por 3 minutos.; (D) Infusão em água a $100^{\circ} \mathrm{C}$ por 6 minutos.

Nota: 1: cafeína; 2: catequina; 3: epigalocatequina galato; 4: rutina; 5: epicatequina.

da cafeína, uma xantina de ação estimulante sobre o sistema nervoso central. Os mesmos tratamentos aplicados à extração dos flavonoides foram usados para a cafeína, que, em chá verde, não deve ultrapassar a concentração máxima de $1 \mathrm{mg} / 100 \mathrm{~g}$ estabelecida pela Anvisa'. No presente estudo, o teor médio de cafeína variou de $M=0,27, D P=0,00 \mathrm{mg} / 100 \mathrm{~g}$ a $M=0,53, D P=0,00$ $\mathrm{mg} / 100 \mathrm{~g}$, quando os tempos de infusão variaram de 1,5 a 6 minutos, o que atesta a conformidade com a legislação vigente das amostras analisadas em relação à cafeína.

\section{Determinação da capacidade antioxidante dos tratamentos de chá verde}

Atividade antioxidante equivalente ao Trolox foi determinada em $\mu \mathrm{Mol} / \mathrm{g}$. A TEAC do chá verde aumentou diretamente com o aumento do tempo de infusão. No entanto, para os sachês extraídos com metanol (99,8\%), a TEAC foi menor quando comparada aos resultados das infusões em água $\left(100^{\circ} \mathrm{C}\right)$ (Figura 3). O comportamento foi semelhante para ambas as marcas, com dife- 
Tabela 1. Quantificação dos compostos extraídos do chá verde com metanol e diferentes tempos de infusão em água a $100^{\circ} \mathrm{C}$. São Cristovão (SE), 2011.

\begin{tabular}{|c|c|c|c|c|}
\hline \multirow{2}{*}{ Compostos extraído } & \multicolumn{4}{|c|}{ Variável $^{*}$} \\
\hline & $\mathrm{MeOH}$ & $1,5 \mathrm{~min}$ & $3,0 \mathrm{~min}$ & $6,0 \mathrm{~min}$ \\
\hline \multicolumn{5}{|l|}{ Cafeína (mg/100g) } \\
\hline Marca1 & $1,54(0,02)^{\mathrm{aA}}$ & $0,27(0,00)^{b D}$ & $0,46(0,00)^{\mathrm{ac}}$ & $0,52(0,00)^{\mathrm{bB}}$ \\
\hline Marca2 & $1,23(0,00)^{\mathrm{bA}}$ & $0,30(0,00)^{\mathrm{aD}}$ & $0,40(0,00)^{\mathrm{bc}}$ & $0,53(0,00)^{a B}$ \\
\hline \multicolumn{5}{|l|}{ Catequina (mg/100g) } \\
\hline Marca1 & $3,10(0,11)^{\mathrm{aA}}$ & $0,18(0,03)^{\mathrm{ad}}$ & $0,70(0,02)^{\mathrm{ac}}$ & $0,86(0,02)^{\mathrm{aB}}$ \\
\hline Marca2 & $2,01(0,04)^{\mathrm{bA}}$ & $0,18(0,01)^{\mathrm{aD}}$ & $0,36(0,02)^{b c}$ & $0,70(0,02)^{\mathrm{bB}}$ \\
\hline \multicolumn{5}{|c|}{ Epigalocatequina (mg/100g) } \\
\hline Marca1 & $24,76(1,19)^{\mathrm{aA}}$ & $1,83(0,01)^{\mathrm{aD}}$ & $3,15(0,01)^{\mathrm{ac}}$ & $4,83(0,07)^{\mathrm{aB}}$ \\
\hline Marca2 & $16,72(0,02)^{\mathrm{bA}}$ & $1,65(0,01)^{\mathrm{bD}}$ & $2,48(0,12)^{\mathrm{bc}}$ & $4,38(0,04)^{\mathrm{bB}}$ \\
\hline \multicolumn{5}{|l|}{ Rutina (mg/100g) } \\
\hline Marca1 & $0,41(0,02)^{\mathbf{b A}}$ & $0,00(0,00)^{\mathrm{aB}}$ & $0,00(0,00)^{\mathrm{aB}}$ & $0,00(0,00)^{\mathbf{b B}}$ \\
\hline Marca2 & $0,73(0,02)^{\mathrm{aA}}$ & $0,00(0,00)^{\mathrm{ac}}$ & $0,00(0,00)^{\mathrm{ac}}$ & $0,17(0,01)^{\mathrm{aB}}$ \\
\hline \multicolumn{5}{|c|}{ Epicatequina (mg/100g) } \\
\hline Marca1 & $8,52(0,46)^{\mathrm{aA}}$ & $0,13(0,02)^{\mathrm{aD}}$ & $0,42(0,01)^{\mathrm{ac}}$ & $0,93(0,06)^{\mathbf{b B}}$ \\
\hline Marca2 & $5,54(0,03)^{\mathrm{bA}}$ & $0,09(0,04)^{b D}$ & $0,35(0,03)^{b c}$ & $0,95(0,20)^{\mathrm{aB}}$ \\
\hline
\end{tabular}

*Média; Desvio-Padrão ( $n=3)$; min: Minutos. Letras minúsculas distintas na mesma coluna e maiúsculas distintas na mesma linha representam diferenças significativas entre as médias pelo teste de Tukey $(p<0,05)$.

Tabela 2. Comparação das características químicas do chá verde de duas marcas diferentes. São Cristovão (SE), 2011.

\begin{tabular}{|c|c|c|c|c|c|}
\hline \multirow{3}{*}{ Análises } & \multicolumn{4}{|c|}{ Valores ${ }^{*}$} & \multirow{3}{*}{$\begin{array}{c}\text { Referência } \\
\text { Brasil }^{1}\end{array}$} \\
\hline & \multicolumn{2}{|c|}{ Marca 1} & \multicolumn{2}{|c|}{ Marca 2} & \\
\hline & M & $\mathrm{DP}$ & M & $\mathrm{DP}$ & \\
\hline Umidade (\%b.u.) & $7,66^{\mathrm{a}}$ & 0,07 & $7,21^{\mathbf{b}}$ & 0,03 & Máximo 12 \\
\hline Cinzas totais (\%) & $4,63^{b}$ & 0,01 & $5,52^{\mathrm{a}}$ & 0,08 & Máximo 8 \\
\hline Cinzas insolúveis em $\mathrm{HCL}$ (\%) & $0,21^{\mathrm{a}}$ & 0,03 & $0,58^{\mathrm{a}}$ & 0,27 & Máximo 1,5 \\
\hline
\end{tabular}

"Média; Desvio-Padrão ( $n=3)$; HCL: Ácido Clorídrico. Letras minúsculas distintas na mesma linha representam diferenças significativas entre as médias pelo teste de Tukey $(p<0,05)$.



Figura 3. Capacidade antioxidante do chá verde extraído com solvente orgânico em diferentes tempos de infusão em água a $100^{\circ} \mathrm{C}$.

Nota: min: Minutos. rença significativa $(p<0,05)$ entre todos os tratamentos, variando de $\mathrm{M}=0,94, \mathrm{DP}=0,94(\mu \mathrm{Mol} / \mathrm{g})$ a $\mathrm{M}=82,14, \mathrm{DP}=2,80(\mu \mathrm{Mol} / \mathrm{g})$, para Marca 1, e de $M=14,21, D P=0,76(\mu \mathrm{Mol} / \mathrm{g}) a \mathrm{M}=93,53, \mathrm{DP}=1,03$ $(\mu \mathrm{Mol} / \mathrm{g})$, para Marca 2 - na extração por metanol e para a infusão água por 6 minutos, respectivamente.

Nishiyama et al. ${ }^{19}$ avaliaram a estabilidade da atividade antioxidante em chá verde e obtiveram $75,0 \%$ de atividade antioxidante no chá preparado em infusão por 5 minutos. Esses resultados evidenciam a elevada capacidade antioxidante do chá verde quando comparado a outros tipos de chá, como no estudo de Morais et al. ${ }^{28}$, 
no qual as amostras mais eficientes em relação aos radicais livres foram: chá verde (Camelia sinensis) com índice capaz de inibir 50\% dos radicais livres $\left(\mathrm{IC}_{50}\right)$ de $0,14 \mathrm{mg} / \mathrm{mL}$; canela (Cinnamonum zeylanicum) $\mathrm{com} \mathrm{Cl}$ 50 de 0,37mg/mL; cravo (Eugenia aromatica) com Cl ${ }_{50}$ de $0,46 \mathrm{mg} / \mathrm{mL}$; louro (Laurus nobilis) com Cl $\mathrm{Cl}_{50}$ de $0,76 \mathrm{mg} / \mathrm{mL}$, e chá preto (Camelia sinensis) com $\mathrm{Cl}_{50}$ de $0,96 \mathrm{mg} / \mathrm{mL}$.

Comparando as amostras desta pesquisa, no tratamento com metanol $(99,8 \%)$ houve diferença significativa $(p<0,05)$ entre elas, sendo a maior média alcançada pela marca $1(21,94 \mu \mathrm{Mol} /$ g). Quando em infusão por 1,5 minuto, as duas marcas não diferiram, e nas infusões por 3 e 6 minutos, a marca 2 foi superior estatisticamente quanto à TEAC, 71,93 e 93,53( $\mu \mathrm{Mol} / \mathrm{g})$, respectivamente.

Os resultados obtidos neste estudo indicam que o chá verde industrializado e comercializado atualmente apresenta elevada capacidade antioxidante, em TEAC, para a infusão aquosa obtida em 6 minutos. Sendo assim, é possível sugerir que, quando o chá verde for consumido com o objetivo de auxiliar na redução ou manutenção do peso corpóreo, o uso da infusão aquosa por 6 minutos extrairá uma maior quantidade das catequinas e também da cafeína, compostos apontados como bioativos funcionais e potenciais no controle da obesidade.

Ferramentas de gestão de obesidade, incluindo a efedrina, cafeína, capsaicina e chá verde, têm sido propostas como estratégias para perda e manutenção de peso, pois podem aumentar o gasto energético. Elas evitam a redução da taxa metabólica que está presente durante a perda de peso ${ }^{29}$. Segundo Diepvens et al. ${ }^{30}$, o chá verde, por conter tanto catequinas quanto cafeína, pode atuar inibindo a atividade da Catecol-O-Metil-Transferase (COMT) e da AMPc-fosfodiesterase, visto que os mecanismos podem também operar sinergicamente. Um possível mecanismo pelo qual a cafeína afeta a termogênese envolve a inibição da AMPc-fosfodiesterase, reduzindo a degrada- ção do AMP cíclico (cAMP) intracelular e estimulando a atividade lipolítica ${ }^{31}$. Processos termogênicos hepáticos, desencadeados por lactato, e a formação de trigliacilgliceróis após a reesterificação hepática também podem explicar a contribuição da cafeína para o efeito termogênico ${ }^{30}$.

As catequinas do chá verde têm propriedades antiangiogênicas que podem impedir o desenvolvimento de sobrepeso e obesidade. Além disso, o sistema nervoso simpático está envolvido na regulação da lipólise e da inervação simpática do tecido adiposo branco, podendo desempenhar um papel importante na regulação da gordura corporal total ${ }^{31}$. Assim, o chá verde, por conter ambas, catequinas e cafeína, pode atuar em diferentes rotas de vias modulatórias, isto é, por meio da AMPc- fosfodiesterase e através da COMT, exercendo, desse modo, um provável efeito termogênico e antiobesidade ${ }^{31}$. No entanto, cabe ressaltar a necessidade de um estudo mais amplo em relação aos tempos de infusão do chá verde a fim de monitorar também a extração ou a formação de substâncias indesejadas (tóxicas) advindas do aumento do tempo de exposição do chá à temperatura de $100^{\circ} \mathrm{C}$.

\section{Composição e qualidade dos chás}

As duas marcas de chá verde apresentaram valores de umidade, cinzas e cinzas insolúveis em Ácido Clorídrico $(\mathrm{HCl})(10 \%)$ abaixo dos índices máximos permitidos pela legislação específica ${ }^{1}$. Houve diferença significativa $(p<0,05)$ entre as marcas apenas para umidade e cinzas totais (Tabela 2). A determinação de cinzas insolúveis em ácido dá uma avaliação da sílica (areia) exis-tente na amostra ${ }^{25}$, e os resultados médios obtidos pelas diferentes marcas de chá, 0,21\% para marca 1 e $0,58 \%$ para a marca 2 , confirmam o encontrado pela microscopia: os índices de sujidades foram inferiores a $150 \mathrm{mg} / 10 \mathrm{~g}$ para ambas. As demais características microscópicas - fragmentos de insetos, elementos histológicos estranhos, amidos e outros - não foram encontradas em nenhuma 
das marcas analisadas. Os resultados descritos atestam a qualidade das duas marcas comerciais de chá verde avaliadas neste estudo, de acordo com os parâmetros estabelecidos na legislação'.

\section{O N C L U S Ã O}

A avaliação do tempo de infusão em água a $100^{\circ} \mathrm{C}$ sobre a disponibilidade dos compostos funcionais cafeína, catequina, epicatequina, rutina e epigalatocatequina em chá verde indicou o tempo de 6 minutos como o ideal para o preparo do chá. A TEAC foi superior nos extratos de chá verde obtidos em 6 minutos de infusão para ambas as marcas avaliadas, com destaque para a marca 2. A extração em metanol foi superior em concentração de compostos bioativos extraídos, mas inferior em TEAC em relação às infusões. $A$ epigalatocatequina foi o composto predominante em ambas as marcas e em todos os tratamentos aplicados neste estudo. Os parâmetros de qualidade físico-químicos e microscópicos estavam em conformidade com a legislação vigente, atestando a qualidade das marcas comerciais de chá verde avaliadas.

\section{A GRADECIMENTOS}

À Coordenação de Aperfeiçoamento de Pessoal de Nível Superior, pelas bolsas concedidas, e ao Conselho Nacional de Desenvolvimento Científico e Tecnológico, pelo apoio financeiro.

\section{COLABORADORES}

JDR PIMENTEL-SOUZA colaborou na concepção, execução de análises de antioxidantes e físico-químicas, análise e interpretação dos resultados e redação. DS SOUZA colaborou na concepção, execução de análises de antioxidantes, físico-químicas e microscópica, análise e interpretação dos resultados e redação. NC GUALBERTO colaborou na execução de análises em Líquida Ultrarrápida, análise e interpretação destes resultados. SA RAMALHO colaborou na execução de análises em Líquida Ultrarrápida, análise e interpretação destes resultados. JJS MOREIRA colaborou na análise e interpretação dos resultados, redação e correção. N NARAIN colaborou na correção.

\section{REFERÊ NCIAS}

1. Brasil. Ministério da Saúde. Secretaria de Vigilância Sanitária. Portaria n 519, de 26 de junho de 1998 Brasília: Anvisa; 1998. [acesso 2012 nov 22]. Disponível em: <http://www.anvisa.gov.br/legis/ portarias/519_98.htm>.

2. Mackay DL, Blumberg JB. The role of tea in human heath: an update. J Am College Nutr. 2002; 21(1): 1-13.

3. Khan N, Mukhtar H. Tea polyphenols for health promotion. Life Sci. 2007; 81(7):519-33. doi: 10.1 016/j.Ifs.2007.06.011.

4. Saldanha LA. Avaliação da atividade antioxidante in vitro de extratos de erva-mate (llexparaguariensis) verde e tostada e chá verde (Camelliasinensis) [dissertação]. São Paulo: Universidade de São Paulo; 2005.

5. Dreosti JE, Wargovich MJ, Yang CS. Inhibition of carcinogenesis by tea: the evidence from experimental studies. Critical Rev Food Sci Nutr. 1997; 37(8):761-70. doi: 10.1080/104083997095 27801.

6. Nishida $H$, Omori $M$, Fukutomi $Y$, Ninomiya $M$, Nishiwaki S, Suganuma $M$, et al. Inhibitory effects of (-)-epigallocatechingallate on spontaneous hepatoma in $\mathrm{C} 3 \mathrm{H} / \mathrm{HeNCrj}$ mice and human hepatoma-derived PLC/PRF/5 cells. Fukushima J Medical Sci. 2010; 56(1):17-29.

7. Cheng TO. All teas are not created equal: the chinese green tea and cardiovascular health. Int J Cardiol. 2006; 108(3):301-8. doi:10.1016/ j.ijcard.2005.05.038.

8. Henry JP, Stephens-Larson P. Reductions of chronic psychosocial hypertension in mice by decaffeinated tea. Hypertension. 1984; 6(3):437-44. doi: 10.1161/01.HYP.6.3.

9. Croft KD. The chemistry and biological effects of flavonoids and phenolic acids. Ann New York Acad Sci. 1998; 854:435-42.

10. Suliburska J, Bogdanski P, Szulinska M, Steptien M, Pupek-Musialik D, Jablecka A. Effects of green tea supplementation on elements, total antioxidants, lipids, and glucose values in the serum of obese patients. Biol Trace Elem Res. 2012; 146(2):1-8. doi: 10.1007/s12011-012-9448-z.

11. Lamarão RC, Fialho E. Aspectos funcionais das catequinas do chá verde no metabolismo celular e 
sua relação com a redução da gordura corporal. Rev Nutr. 2009; 22(2):257-69. doi:10.1590/\$141 5-52732009000200008.

12. Trudel D, Labbé DP, Bairati I, Fradet V, Bazinet L, Têtu B. Green tea for ovarian cancer prevention and treatment: a systematic review of the in vitro, in vivo and epidemiological studies. Gyn Onc. 2012; 126(3):491-98. doi:10.1016/j.ygyno.2012.04.048.

13. Hampton ME. Production of black tea. In: Willson KC, Clifford MN, editors. Tea cultivation to consumption. London: Chapman \& Hall; 1992.

14. Lima JD, Mazzafera P, Moraes WS, Da Silva RB. Chá: aspectos relacionados à qualidade e perspectivas. Ciênc Rural. 2009; 39(4):1270-8. doi: 10.1590/S0 103-84782009005000026.

15. Armoskaite $V$, Ramanauskiene K, Maruska A, Razukas A, Dagilyte A, Baranauskas A, et al. The analysis of quality and antioxidant activity of green tea extracts. Med Plant Res. 2011; 5(5):811-6.

16. Matsubara DB, Rodriguez-Amaya DB. Teores de catequinas e teaflavinas em chás comercializados no Brasil. Ciênc Tecnol Aliment. 2006; 26(2):401-7. doi: 10.1590/S0101-20612006000200024.

17. Anon. International Tea Committee. London: Annual Bulletin of Statistics; 2001.

18. Ravichandran R, Parthiban R. The impact of mechanization of tea harvesting on the quality of south indian CTC teas. Food Chem. 1998; 63(1):614. doi: 10.1016/S0308-8146(97)00219-7.

19. Nishiyama MF, Costa MAF, Costa AM, Souza CGM, Bôer CG, Bracht CK, et al. Chá verde brasileiro (Camelliasinensis var assamica): efeitos do tempo de infusão, acondicionamento da erva e forma de preparo sobre a eficiência de extração dos bioativos e sobre a estabilidade da bebida. Ciênc Tecnol Aliment. 2010; 30(Supl 1):191-6. doi:10.1590/S0 101-20612010000500029.

20. Rufino MSM, Alves RE, Brito ES, Morais SM, Sampaio CG, Péres-Jiménez J, et al. Metodologia científica: determinação da atividade antioxidante total em frutas pela captura do radical livre ABTS •+. Fortaleza: Embrapa Agroindústria Tropical; 2007.

21. Xu Y-Q, Chen G-S, Wang Q-S, Yuan H-B, Feng C-H, Yin J-F. Irreversible sediment formation in green tea infusions. J Food Sci. 2012; 77(3):C298-C302, doi: 10.1111/j.1750-3841.2011.02583.x.

22. Vuong QV, Golding JB, Stathopoulos CE, Nguyen $\mathrm{MH}$, Roach PD. Optimizing conditions for the extraction of catechins from green tea using hot water. J Separation Sci. 2011; 34(21):3099-106. doi: 10.1002/jssc.201000863.

23. Souza MM, Recart VM, Rocha M, Cipolatti EP, Badiale-Furlong E. Estudo das condições de extração de compostos fenólicos de cebola (Allium cepa L.). Rev Instituto Adolfo Lutz. 2009; 68(2):192-200.

24. Saito ST, Welzel A, Suyenaga ES, Bueno F. A method for fast determination of epigallocatechin gallate (EGCC), epicatechin (EC), catechin (C) and caffeine (CAF) in green tea using HPLC. Ciênc Tecnol Aliment. 2006; 26(2):394-400. doi: 10.1590/S0 101-20612006000200023.

25. Instituto Adolfo Lutz. Normas analíticas do Instituto Adolfo Lutz. 4a ed. São Paulo: IAL; 2004.

26. Romeo L, Intrieri M, D'Agata $V$, Mangano NG. The major green tea polyphenol, (-)-epigallocatechin3- gallate, induces hemeOxygenase in rat neurons and acts as an effective neuroprotective Agent against oxidative stress. J Am Col Nutr. 2009; 28(4): 492s-9s.

27. Pekal A, Drozdz P, Biesaga M, Pyrzynska K. Screening of the antioxidant properties and polyphenol composition of aromatized green tea infusions. J Sci Food Agric. 2012; 92(11):2244-9. doi: 10.1002/jsfa.5611.

28. Pelillo M, Biguzzi B, Bendini A, Gallina-Toschi T, Vanzini M, Lercker $G$. Preliminary investigation into development of HPLC with UV and MS-electrospray detection for the analysis of tea catechins. Food Chem. 2002; 78(3):369-74. doi: 10.1016/S0308-8 146(02)00112-7.

29. Morais SM, Cavalcanti ESB, Costa SMO, Aguiar LA. Ação antioxidante de chás e condimentos de grande consumo no Brasil. Rev Bras Farmacogn. 2009; 19(1B)315-20. doi: 10.1590/S0102-695X20 09000200023

30. Diepvens K, Westerterp KR, Westerterp-Plantenga MS. Obesity and thermogenesis related to the consumption of caffeine, ephedrine, capsaicin, and green tea. Am J Physiol Regul Integr Comp Physiol. 2007; 292(1):R77-R85. doi: 10.1152/ajprgu.008 32.2005.

31. Dulloo AG. Ephedrine, xanthines and prostaglandininhibitors: actions and interactions in the stimulation of thermogenesis. Int J Obes Relat Metab Disord. 1993; 17(1):s35-s40.
Recebido em: 2/12/2011 Versão final em: 3/7/2012 Aprovado em: 20/8/2012 
